\title{
Proposal for improved nuclear fuel utilisation and economic performance by utilising thorium
}

\author{
Marina du Toit \\ Eskom and PhD student, Post Graduate School for Nuclear Science and Engineering, North West University, \\ South Africa
}

\section{Sunil Chirayath}

Nuclear Security Science \& Policy Institute, Texas A\&M University and Nuclear Engineering Department, TAMU

\begin{abstract}
A systematic and strategic nuclear power reactor deployment roadmap has been developed for South Africa within the national strategic plan, utilizing thorium-based fuel. The roadmap was developed through analysis of economical, strategic and historical aspects. The accumulated advantages of thorium-based fuels are summarized, which could form the initiative to implement thorium-based nuclear fuels in South Africa.

A timeline (which forms the basis of the roadmap) was constructed and consists of three different phases. Phase 1 starts in 2015 and extends to 2030. Phase 2 starts in 2031 and ends in 2044 whilst Phase 3 is from 2045 to 2060. Each phase is discussed with regard to construction, implementation and research activities. This roadmap starts at current pressurized water reactors (PWRs) and advances to future reactor technologies, using an evolutionary approach.

In addition to the results reported in this paper, the economic advantages to introducing thorium as a fertile component in PWR fuels as compared to once-through conventional uranium-only cycles is explored (Du Toit \& Cilliers, 2014). The economic evaluation compares uranium fuel to thorium-uranium fuel in terms of the fuel cycle costs, reactor downtime costs due to refuelling and income derived from electricity sales.
\end{abstract}

Keywords: thorium-based fuels, PWR, roadmap, fuel cycle, nuclear power in South Africa

\section{Introduction}

The world is facing the reality of increasing electricity demand and depleting natural resources. The recent focus on clean energy and security-of-supply has forced countries to diversify their electricity grid in order to become less dependent on fossil fuels such as coal, gas and oil. Uranium supplies, like any natural resource, are limited and uranium carries the risk of price escalations. Diversity of fuel sources other than uranium needs to be considered for nuclear power to be sustainable into a long future.

Nuclear technology for electricity production has received increased attention in South Africa (SA), especially after the South African government published the IRP2010 (Integrated Resource Plan) (SA, 2010). The South African IRP2010 requires building of new nuclear power reactors (most likely PWRs) with a generation capacity of $9600 \mathrm{MWe}$ before the end of 2030. New reactors are planned and the rate of building is restricted to one reactor every 18 months, the first reactor is scheduled for commissioning in 2023. South African policy, aimed at an increased nuclear power share, can be attributed to the depletion of coal resources, a move away from coal based electric generation as baseload power, to diversify and to focus on increasing electricity generation from carbon emission-free resources.

Uranium mined from its ore is the common fuel used in nuclear power reactors for electricity generation and to a lesser extent plutonium (a by-product in used uranium fuel). Thorium is another potential material which can be used in reactors to breed fissile fuel material, ${ }^{233} \mathrm{U}$ (man-made isotope of uranium compared to natural uranium isotopes, ${ }^{235} \mathrm{U}$ and $\left.{ }^{238} \mathrm{U}\right)$. Transmutation of thorium $\left({ }^{232} \mathrm{Th}\right)$ to ${ }^{233} \mathrm{U}$ fuel through neutron irradiation in a nuclear reactor can be seen as a driver for fuel sustainability in nuclear power reactors. The challenge is that the uranium $\left({ }^{233} \mathrm{U}\right)$ bred from thorium has to be recov- 
ered and the process must also be economically competitive compared to the uranium $\left({ }^{235} \mathrm{U}+\right.$ $\left.{ }^{238} \mathrm{U}\right)$ produced through mining and enrichment. Uranium resources are expected to deplete, being the sole resource for supplying fuel to about 435 nuclear power reactors currently in operation and 71 under construction worldwide, which will bring up the prominence of thorium (WNA, 2014).

Thorium deployment in nuclear power reactors has been studied during the 1950s, but was not commonly employed due to the abundance and also lower cost of mining uranium (Trellue et al., 2011). There is a renewed interest in thorium for reasons elaborated in Section 1.1 and the International Atomic Energy Agency (IAEA) has released several reports on thorium utilization in nuclear reactors (IAEA, 2000; IAEA, 2002; IAEA, 2003; IAEA, 2005). The feasibility of mixing thorium and plutonium fuel in existing PWRs has been the focus of some recent studies (Trellue et al., 2011; Fridman \& Kliem, 2011; Bjork, 2012). This fuel mix is especially used to optimize the plutonium destruction rate (Schram \& Klaassen, 2007). Mixed thorium and uranium fuels in PWRs have been studied (Herring et al., 2001; Weaver \& Herring, 2002; Wilson et al., 2009). Thorium-plutonium mixed oxide fuel pins of Boiling Water Reactor (BWR), Pressurized Heavy Water Reactor (PHWR) and Advanced Heavy Water Reactor (AHWR) design have been tested in Indian research reactors, CIRUS and DHRUVA (BARC, 2014). The total thorium resources in $\mathrm{SA}$ are estimated at around 55,000 tonnes (Van Rooyen et al., 2012).

This study develops a roadmap for electricity generation from nuclear fuel resources in South Africa, utilizing thorium as a fuel. The advantages to implement thorium-based fuels are discussed. The roadmap is then developed and discussed to provide scope for policy-makers and government. The assumptions in developing the roadmap in three phase are described and each phase is described in terms of construction, implementation and research activity needs.

The economic advantages of introducing thorium as a fertile component in PWR fuels are explored as compared to once-through conventional uranium-only cycles (Du Toit \& Cilliers, 2014). The economical evaluation and comparison of uranium fuel and thorium-uranium fuel in terms of the fuel cycle costs, reactor downtime costs due to refuelling and income derived from electricity generation are presented.

\subsection{Advantages of thorium-based fuel}

The advantages of thorium-based fuels are summarized in this section and all these advantages underlie the initiative to implement thorium-based fuels in South African nuclear power reactors.

Thorium is said to be between three to four times more abundant than uranium (Trellue et al., 2011; WNA, 2011). Thorium-based fuels have greater potential to produce more fuel material (uranium) in reactors compared to uranium-based fuels producing fuel material plutonium (Kang-Mok \& Myung-Hyung, 2005). Uranium produced from thorium has better fuel properties to enhance reactor safety, and to efficiently generate electricity (Trellue et al., 2011). Thorium dioxide $\left(\mathrm{ThO}_{2}\right)$ is more stable and robust than Uranium dioxide $\left(\mathrm{UO}_{2}\right)$ in fuel fabrication fuel from a metallurgical (Caner \& Dugan, 2000) and chemical point of view. $\mathrm{ThO}_{2}-\mathrm{UO}_{2}$ and $\mathrm{ThO}_{2}-\mathrm{PuO}_{2}$ fuel combinations have better heat-transfer properties leading to lower fuel failures (Bjork, 2012). The higher melting point of $\mathrm{ThO}_{2}$ aids in better utilization of fuel (Trellue et al., 2011) and higher fuel utilization will extend refuelling time of the reactors, which in turn, reduces the fuel requirements and reduces used fuel management efforts. Extended re-fuelling cycles also reduce the reactor downtime for re-fuelling, which increases the reactor availability and capacity factors.

Thorium-based fuels are found to better alleviate the nuclear weapons material proliferation concerns compared to that of uranium-plutonium mixed oxide fuel (Herring et al., 2001). Mixed oxides of $\mathrm{ThO}_{2}-\mathrm{PuO}_{2}$ fuel can achieve two times higher plutonium destruction rates compared to $\mathrm{UO}_{2}-\mathrm{PuO}_{2}$. This reduces the material attractiveness of plutonium (with regard to proliferation) in the used $\mathrm{ThO}_{2}-\mathrm{PuO}_{2}$ fuel because of reduced plutonium inventory (Trellue et al., 2011). The uniformity of power production within the reactor core is a desirable reactor safety feature and is found to be better in $\mathrm{ThO}_{2}-\mathrm{UO}_{2}$ and $\mathrm{ThO}_{2}-\mathrm{PuO}_{2}$ fuelled reactors (Fridman \& Kliem, 2011).

Based on the economic and technical advantages, along with the historic examples that suggests evolutionary introduction of new technology tend to be more successful than revolutionary changes. An evolutionary approach in the development of the aforementioned roadmap is taken by recommending the introduction $\mathrm{ThO}_{2}-\mathrm{UO}_{2}$ fuel assemblies in place of pure $\mathrm{UO}_{2}$ fuel assemblies in the existing Pressurized Water Reactor (PWR) which results in a better fertile to fissile material conversion ratio, longer re-fuelling cycles and ultimately a reduction in operating cost. These changes result in slightly different operating parameters but the operating philosophy remains unchanged (Du Toit, 2012).

\section{Roadmap}

The advantages of thorium-based fuel and the historical, economical, strategic and technical aspects are taken into account to develop a nuclear power roadmap for South Africa and to provide the scope for policy-makers. 
The roadmap consists of three different phases. Phase 1 starts in 2015 and extends to 2030. Phase 2 starts in 2031 and ends in 2044 and Phase 3 from 2045 to 2060 . Each phase is discussed with regard to construction, implementation and research needs. This roadmap will progress and advance to future technologies using an evolutionary approach.

\subsection{Assumptions}

1. Six reactors are planned with a building rate of one reactor every 18 months; the first reactor being envisaged for commissioning in 2023 (SA, 2010). It is assumed that there will be a one-year delay and the first reactor will start operation in 2024.

2. The reactor construction duration is assumed to be four years (Koomey \& Hultman, 2007).

3. It is estimated to take ten to fifteen years for introducing new fuels into modern reactors and it is assumed that the thorium-based fuel cycle could be deployed in the newly built reactors within the next fifteen years, which is comparable to the period that was required to implement mixed oxide fuel in PWRs elsewhere (Hesketh \& Worall, 2010).

4. It is assumed that South Africa will start to build its own fuel production, fabrication- and fuel reprocessing plants in 19 years', which is two years after the $6^{\text {th }}$ new reactor, will have been commissioned. This will correspond to the suggestion from Eskom Holdings SOC Limited to develop the fuel cycle facilities together with the reactor programme.

5. The used $\mathrm{UO}_{2}$ fuel in PWRs is cooled for five years before it is chemically reprocessed to recover useful plutonium and uranium (Rose et al., 2011).

6. The reprocessing duration after the cooling period is assumed to be two years (Shelley et al., 2000).

7. The construction of the reprocessing facility would take up to ten years (Schneider et al., 2009).

8. It is assumed that the lifetime of the two PWRs currently operating in Koeberg, SA will be extended from 40 years to 60 years.

9. A new Accelerator Driven System (ADS), envisaged to incinerate nuclear waste and to produce electricity, needs a minimum of 40 years to be designed, built and reach commercial maturity (Hesketh \& Worall, 2010). It is assumed that the first ADS will operate 45 years from now.

10.The annual discharge of recyclable plutonium from a standard PWR is about $250 \mathrm{~kg}$ (Galperin et al., 1997).

All of these assumptions result in a timeline as shown in Figures 1 and 2, depending on the scenarios chosen in Phase 2. These timelines form the basis of the roadmap and will now be discussed in more detail.

\subsection{Phase 1 (2015-2030)}

Phase 1 describes the starting point of the roadmap to implement thorium-based fuels in PWRs as well as the construction of the six planned reactors.

\subsubsection{Construction}

The first reactor starts construction in 2019 and will be commissioned in 2024, followed by three new reactors online in 2025, 2026 and 2027. The remaining two reactors will be commissioned in 2029 and 2030. During this time, South Africa

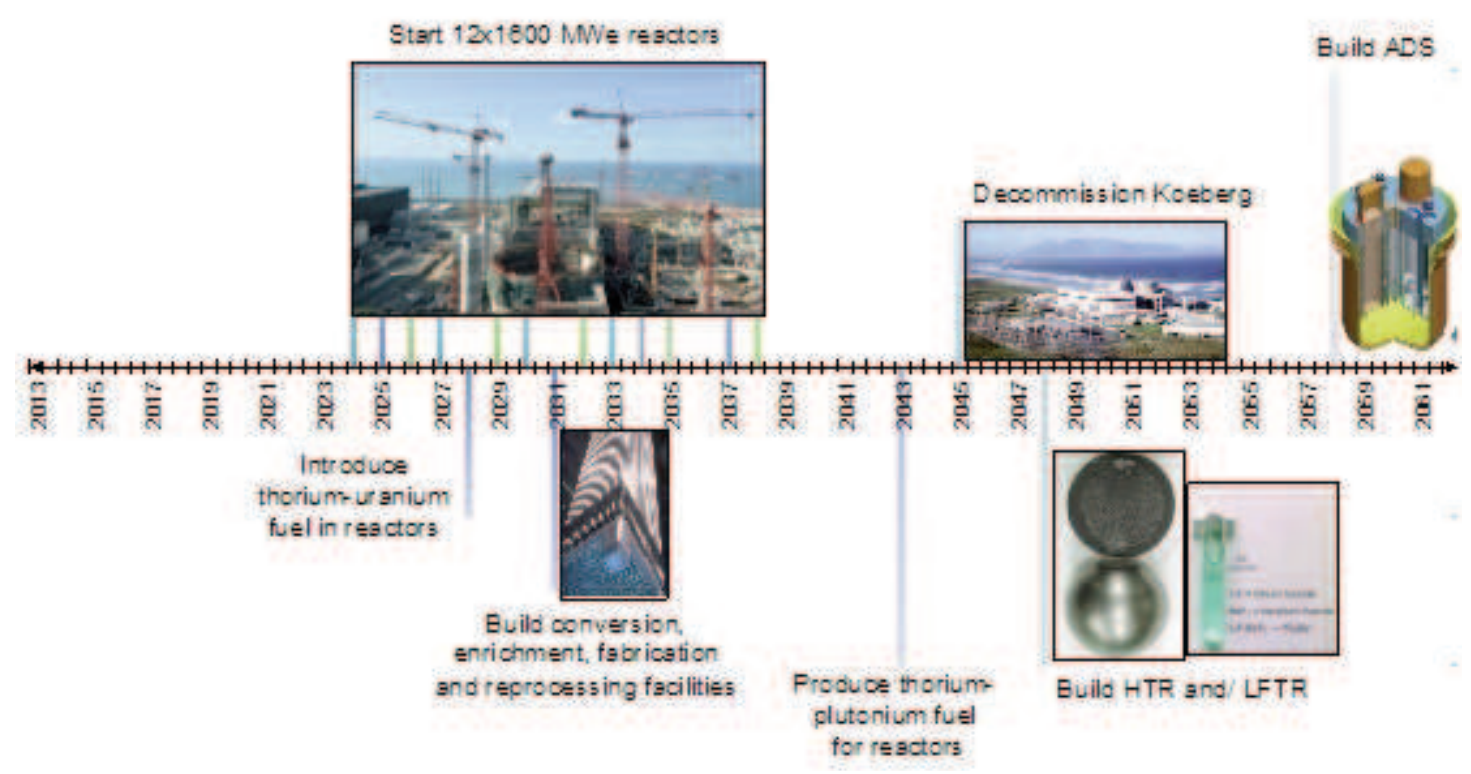

Figure 1: Thorium fuel introduction roadmap for Scenario A 


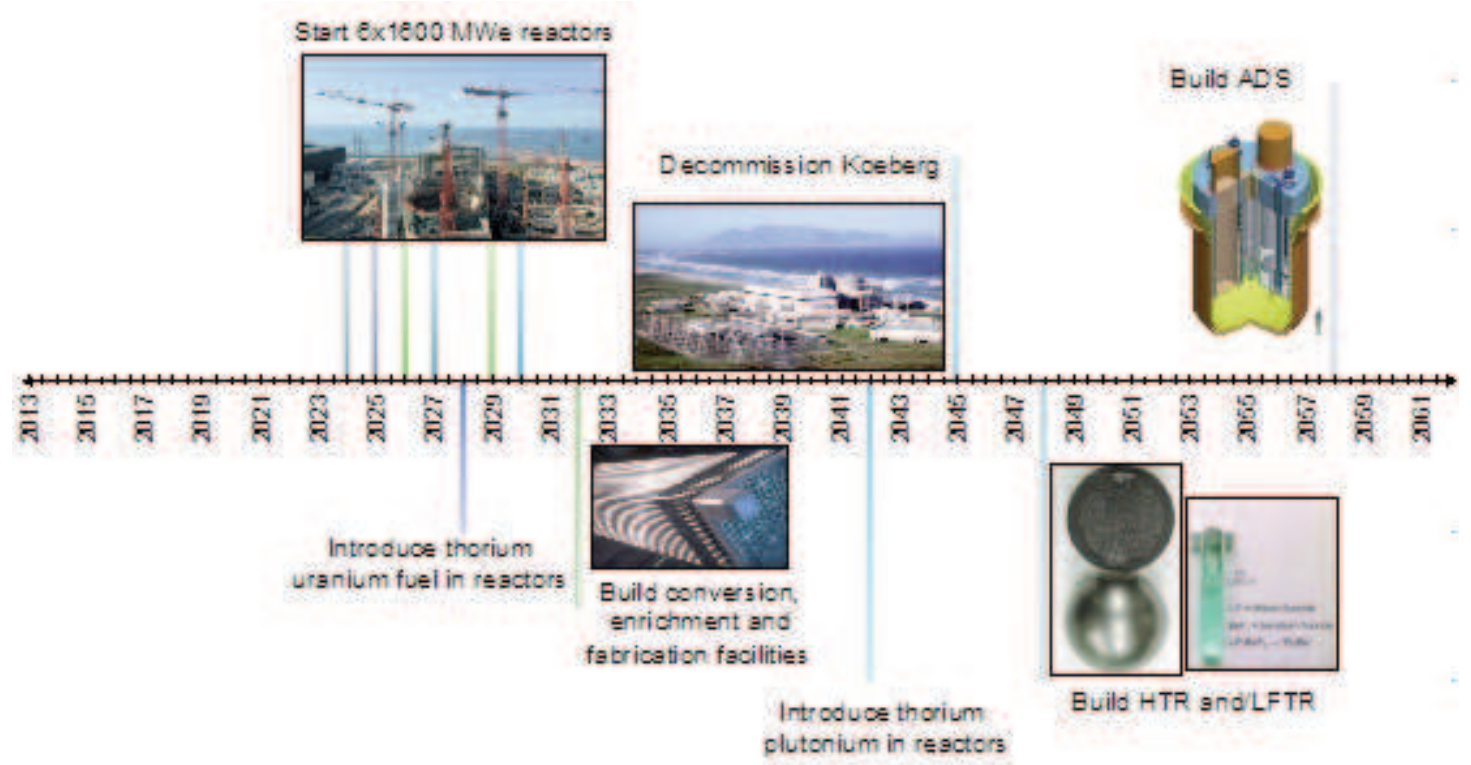

Figure 2: Thorium introduction roadmap for Scenario B

should obtain as much as possible experience and skills from the vendor/vendors building these reactors. Local contractors and manufacturers should be involved in the nuclear expansion programme and start to work independently on the last two reactors.

\subsubsection{Implementation}

In 2028, thorium-based fuels would be introduced in the one completed reactor, assuming the construction period to be four years for each new reactor. The choice for the thorium-based fuel for Phase 1 would be, once through $\mathrm{ThO}_{2}-\mathrm{UO}_{2}$ fuel with special coating and fuel cladding materials, increasing coolant water inside the reactor as well as reactor control materials like boron.

The reason for choosing $\mathrm{ThO}_{2}-\mathrm{UO}_{2}$ fuel than $\mathrm{ThO}_{2} \mathrm{PuO}_{2}$ fuel is, because there is more open literature on investigations of the former than the latter (Schram \& Klaassen, 2007). Also, uranium mining has already been established in SA, and currently $\mathrm{SA}$ has no plutonium $(\mathrm{Pu})$ reprocessing facility to recycle $\mathrm{Pu}$ to use in $\mathrm{ThO}_{2}-\mathrm{PuO}_{2}$ fuels. $\mathrm{ThO}_{2}-\mathrm{UO}_{2}$ fuel has also proved to be more economical than $\mathrm{ThO}_{2}-\mathrm{PuO}_{2}$ fuel unless the cost of plutonium reprocessing and the corresponding fuel fabrication could be reduced. The proposed fuel cycle with thorium deployment is shown in Figure 3.

\subsubsection{Research requirements}

During Phase 1, investigations should focus on $\mathrm{ThO}_{2}-\mathrm{UO}_{2}$ and $\mathrm{ThO}_{2}-\mathrm{PuO}_{2}$ fuel deployment challenges such as;

- Reactor performance characterization with $\mathrm{ThO}_{2}-\mathrm{UO}_{2}$ fuel instead of the conventional $\mathrm{UO}_{2}$ fuel used in PWRs.

- Reactor performance characterization with $\mathrm{ThO}_{2}-\mathrm{PuO}_{2}$ fuel instead of the conventional $\mathrm{UO}_{2}$ fuel used in PWRs.
- Reducing the reprocessing cost to deploy $\mathrm{ThO}_{2}$ $\mathrm{PuO}_{2}$ fuels in PWRs in the future.

- Research and Development into the planning, construction of a fuel fabrication facility and a reprocessing facility, from here on called fuel cycle facilities.

The implementation of the required fuel cycle facilities (excluding the nuclear reactors) is projected at a cost of $\$ 6.15$ billion (Balack, 2010). The applications for funding to support the fuel cycle

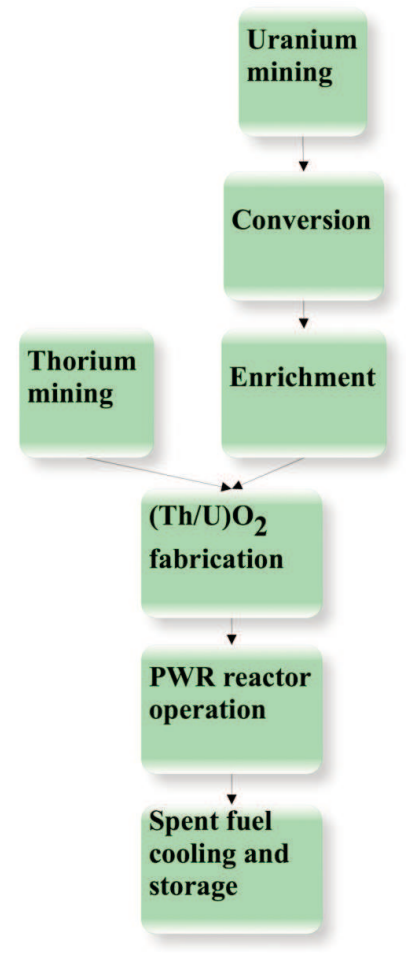

Figure 3: Fuel cycle for thorium deployment in Phase 1 of the roadmap 
facilities development should be in progress at this time. The option to develop thorium-based fuels should be pursued in collaboration with other international partners.

As shown in Figures 1 and 2, other than PWRs, it is proposed to deploy technologically different but newer types of nuclear power reactors in SA. They are High-Temperature Reactors, Liquid Fluoride Thorium Reactors and Accelerator Driven System. Research should commence on these newer nuclear power systems as well.

The manufacture of fuels based on uranium $\left({ }^{233} \mathrm{U}\right)$, recovered through chemical reprocessing of thorium fuel discharged from the reactors has challenges associated with it, which could turn out to be very expensive than conventional natural uranium $\left({ }^{235+238} \mathrm{U}\right)$ fuel fabrication. Hence, research should also focus on streamlining the $233 \mathrm{U}$-based fuel fabrication process and reducing the chemical reprocessing cost of such fuels, by simplifying this process, or by a combination of all these factors (Lung \& Gremm, 1998; BARC, 2014).

\subsection{Phase 2 (2031-2044)}

Two different scenarios are sketched for Phase 2, the first (scenario A) assuming that government decides to continue the nuclear reactor building programme after 2030 (refer to Figure 1). The second scenario assumes that the nuclear reactor building programmes stop in 2030 with no support to build a used fuel reprocessing plant (refer to Figure 2).

\subsubsection{Phase 2A}

Phase 2A focuses on the construction of the uranium enrichment and fuel fabrication plants to produce $\mathrm{ThO}_{2}-\mathrm{UO}_{2}$. The main reasons for building local fuel cycle facilities are to make sure of security of fuel supply and the usage of locally-mined uranium and thorium. Phase $2 \mathrm{~A}$ also focuses on building a reprocessing facility and producing $\mathrm{ThO}_{2}-\mathrm{PuO}_{2}$ fuel. It should be noted that reprocessing is an expensive and sensitive step in the fuel cycle and depends on the local demand. The cost of conversion, enrichment, fabrication and reprocessing plants is estimated at $\$ 6.2$ billion (Balack, 2010).

\subsubsection{Construction}

Construction on the nuclear fuel cycle facilities (including plants for conversion, enrichment, fabrication and used fuel reprocessing) will start in 2031 and construction is assumed to continue for 10 years. In 2041, the fuel cycle facilities should be online and be ready to recycle plutonium $(\mathrm{Pu})$ and produce $\mathrm{ThO}_{2}-\mathrm{PuO}_{2}$ fuel. It is assumed that the same building schedule for nuclear reactors be followed as in Phase 1 starting with the commissioning of the first reactor in 2035. The construction of these six reactors will be easier at this time due to the experience gained from the first six reactors.

\subsubsection{Implementation}

$\mathrm{ThO}_{2}-\mathrm{PuO}_{2}$ fuel could be introduced in reactors by middle of 2043, assuming a reprocessing period of two years and another six months for fuel fabrication. The choice for the thorium-based fuel for Phase 2 would be $\mathrm{ThO}_{2}-\mathrm{PuO}_{2}$. The reasons for choosing $\mathrm{ThO}_{2}-\mathrm{PuO}_{2}$ are due to the used fuel accumulation at the currently operating PWRs at Koeberg and at new plants as well so as to reduce the waste stockpiles. According to simplified calculations, the accumulated plutonium can supply approximately 12 re-fuelling cycles of the reactor.

$\mathrm{ThO}_{2}-\mathrm{PuO}_{2}$ fuel improves proliferation resistance reduces waste with no new plutonium and relieves some of the uranium requirements. The reactor-grade $(R G)$ plutonium is recycled from current Koeberg used fuel and mixed with thorium. The proposed fuel cycle is shown in Figure 4.

It should be noted that South Africa agreed that they would not reprocess their used fuel to recover plutonium. Commercial possibilities to reprocess used fuel overseas should be arranged. SA can also import reprocessed plutonium for the $\mathrm{ThO}_{2}-\mathrm{PuO}_{2}$ fuel option, but concerns about plutonium diversion for non-peaceful uses can cause impediments to this import.

Figure 4: Fuel cycle for Phase 2A of the

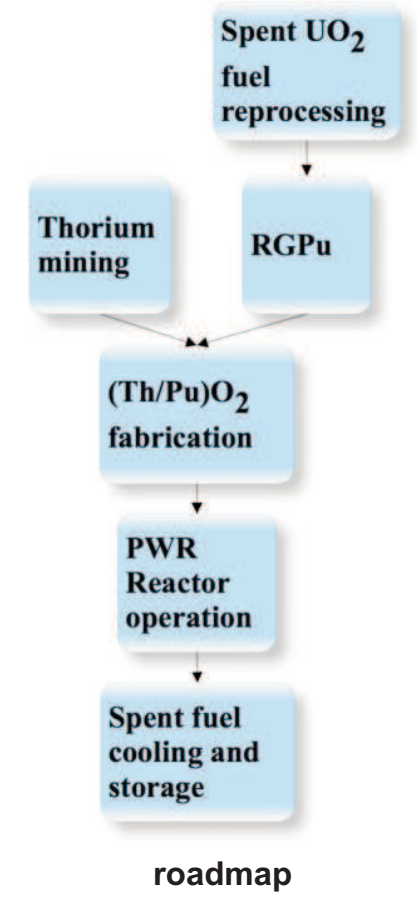

\subsubsection{Research requirements}

The behaviour of $\mathrm{ThO}_{2}-\mathrm{PuO}_{2}$ fuel in the new PWRs should be investigated, analysed and optimized.

The option to develop thorium-based fuels, not only for SA, but also in the future for the whole world should be researched (BARC, 2014). As 
shown in Figures 1 and 2, it is proposed to implement HTRs, LFRs and ADS in future. Research on these nuclear power systems (HTRs, LFTRs and ADS) should be complete and should be moving into the design stages.

A permanent and sustainable fuel cycle involves utilizing uranium $\left({ }^{233} \mathrm{U}\right)$ bred from thorium-based cycles. The manufacture of ${ }^{233} \mathrm{U}$-based fuels has challenges and needs to be made cost-effective and safe through $R \& D$ focusing on streamlining the fuel fabrication process and reducing the reprocessing cost of such fuels, by simplifying this process, or by a combination of all these factors (Kang-Mok \& Myung-Hyung, 2005).

\subsubsection{Phase $2 B$}

The only difference here compared to Phase 2A is that chemical reprocessing of used fuel is not envisaged here. The reason for this is that eight reactors in total may not validate the capital investment in such a reprocessing facility. The cost of implementing the conversion plant, enrichment plant and fuel fabrication plant is approximately $\$ 3.6$ billion (Balack, 2010).

\subsubsection{Construction}

Construction of the nuclear fuel facilities (including conversion, enrichment and fabrication facilities) will start in 2032 and construction is assumed to continue for ten years. In 2042 the fuel facility should be online and ready to produce $\mathrm{ThO}_{2}-\mathrm{UO}_{2}$ (note the difference in this scenario, as uranium, instead of plutonium is mixed with thorium, due to the fact that plutonium will be hard to come by without a reprocessing plant).

\subsubsection{Implementation}

The implementation activity for Phase $2 \mathrm{~B}$ is similar to Phase 1 , as the fuel is now only produced locally in South Africa. In 2042, the locally produced $\mathrm{ThO}_{2}-\mathrm{UO}_{2}$ fuels would be introduced into the remaining reactors. The choice for the thoriumbased fuel for Phase 2B would be that it is once through (no recycling) $\mathrm{ThO}_{2}-\mathrm{UO}_{2}$ fuel with a special coating and fuel cladding materials, with increasing coolant water inside the reactor as well as reactor control materials like boron. The proposed fuel cycle is shown in Figure 5.

\subsubsection{Research requirements}

The behaviour of $\mathrm{ThO}_{2}-\mathrm{UO}_{2}$ fuel in the new PWRs should be investigated, analysed, and optimized. The option to develop thorium-based fuels, not only for SA, but also internationally, should be researched and pursued. As shown in Figures 1 and 2 , it is proposed to implement HTRs, LFTRs and ADS in future. Research should commence on these systems (HTRs, LFRs and ADS).

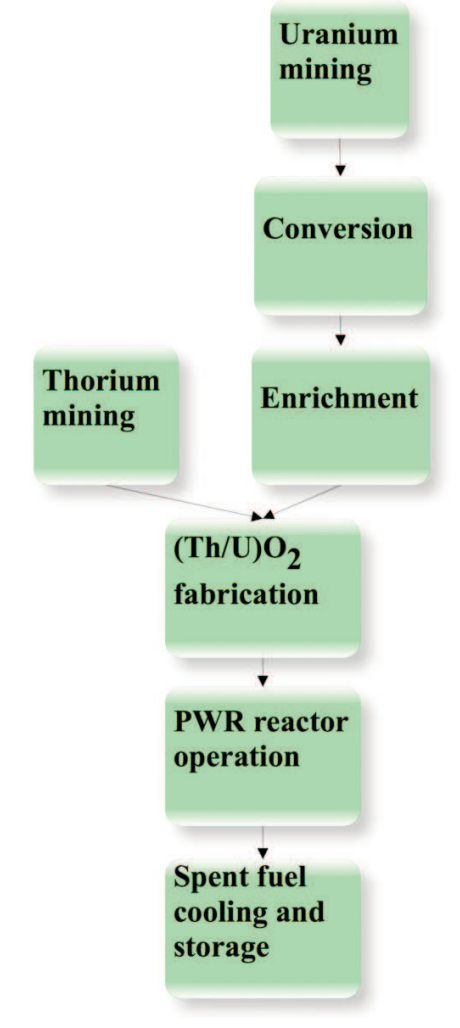

\section{Figure 5: Fuel cycle for Phase 2B of the roadmap}

\subsection{Phase 3 (2045-2060)}

Phase 3 consists of inducting $\left(\mathrm{Th} /{ }^{233} \mathrm{U}\right) \mathrm{O}_{2}$ into PWRs and building and planning thorium specific reactor designs such as the LFTR, ADS and the HTR. Please note that some of these reactors can reach commercial maturity before 2045, for instance, HTRs. HTRs and LFTRs both have continuous online re-fuelling, which completely eliminates the re-fuelling outage costs to the utility.

\subsubsection{Construction}

Koeberg would be decommissioned in 2045. HTRs and LFTRs should start construction in 2048. The number of reactor and reactor type would be based on the electricity demand and technological maturity. The ADS should start construction in 2058.

\subsubsection{Implementation}

$\mathrm{ThO}_{2}-\mathrm{PuO}_{2}$ fuel discharged from Phase 2 PWRs is cooled for five years and will be reprocessed to extract the uranium $\left({ }^{233} \mathrm{U}\right)$ produced from thorium. This extracted uranium can be used to manufacture $\mathrm{ThO}_{2} / 233 \mathrm{UO}_{2}$ fuel and can be loaded into the periphery of PWR to compose so-called 'blanket' to help increase the re-fuelling time of the reactor. This cycle can be continued with the recycling of ${ }^{233} \mathrm{U}$ repeatedly $(\mathrm{Si}, 2009)$. The proposed fuel cycle is shown in Figure 6.

\subsubsection{Research requirements}

Research should focus on the optimisation of the 


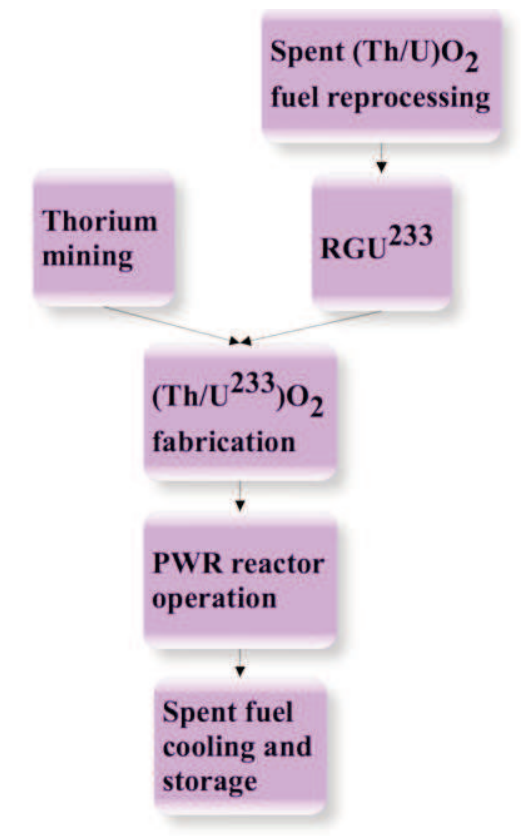

Figure 6: Fuel cycle for Phase 3 of the roadmap

entire current reactor systems as well as fuel performance. Possibilities to produce fuel for international markets should be explored.

\section{Conclusions}

A three-phase pragmatic approach is taken to develop an evolutionary strategic roadmap to introduce and implement thorium-based fuels in the South African nuclear power reactor building programme. It has been described in terms of construction, implementation and research activities. The strategic roadmap is based on historical, technical, strategic and economical aspects as well as based on the advantages of thorium-based fuels. An evolutionary strategy of introducing thoriumbased fuels into existing and future reactor technologies is developed.

Thorium-based fuels can supplement uranium to diversify the natural nuclear fuel resources and increase the nuclear energy sustainability. Thoriumbased fuels can incinerate plutonium, enhance fuel utilization and extend re-fuelling cycles of the reactor, which adheres to current governmental initiatives. SA can utilize local resources (Thorium, currently stockpiled) to enhance fuel utilization.

The thorium-based fuel implementation strategy fits in with the government policy and can pay for the front-end fuel cycle facilities by saving on fuel cycle costs and re-fuelling outage costs. The proposed strategy can help SA to become fuel-independent, help Eskom Holdings SOC Limited (current nuclear operator in SA) to keep the power on for longer period and create local job opportunities. Safety is increased with higher proliferation resistant fuels and advanced reactor technologies.

\section{Acknowledgements}

This work was supported by the South African utility, Eskom and the National Research Foundation (NRF).

\section{References}

Balack P.A. (2010). Framework for the cost of policy implementation of the South African nuclear expansion program. North-West University (Dissertation, M Eng).

BARC (Bhabha Atomic Research Centre), Department of Atomic Energy, Government of India (2014). Thorium fuel cycle in India.

http://www.barc.gov.in/reactor/tfc.html Date of access: 04 May 2015.

Bjork K.I. (2012) Thorium-plutonium fuel for long operating cycles in PWR's - Preliminary calculations, Paper presented the Thorium and Rare Earths 2012, Cape Town, 22 February.

Caner M. \& Dugan E.T. (2000). ThO2-UO2 annular pins for high burnup fuels. Annals of nuclear energy, 27 (2000) 759-770.

Du Toit M.H. \& Cilliers A.C. (2014). Preliminary Economic Evaluation of Thorium-Based Fuels in PWRs, American Nuclear Society, Nuclear Technology 187:3 (2014) 260-269.

Du Toit, M.H. (2012). Introducing advanced thoriumbased fuel cycles in SA: an evolutionary approach. North-West University (Dissertation, M Eng).

Fridman E. \& Kliem S. (2011). Pu recycling in a full ThMOX PWR core. Part I: Steady state analysis. Nuclear engineering and design, 241 (2011) 193202.

Galperin A., Reichert P. \& Radkowsky A. (1997). Thorium Fuel for Light Water Reactors Reducing Proliferation Potential of Nuclear Power Fuel Cycle. Science Global Security, 6, 265-290.

Herring J.S., Macdonald P.E., Weaver K.D \&. Kullberg C. (2001). Low cost, proliferation resistant, uranium-thorium dioxide fuels for light water reactors. Nuclear engineering and design, 203, 65-85.

Hesketh K. \& Worall A. (2010). The Thorium Fuel Cycle, An independent assessment by the UK National Nuclear Laboratory, Position Paper.

IAEA (International Atomic Energy Agency). (2000). Thorium based fuel options for generation of electricity developments in the 1990s. IAEA-TECDOC1155.

IAEA (International Atomic Energy Agency). (2002). Thorium fuel utilization Options and Trends. IAEATECDOC-1319.

IAEA (International Atomic Energy Agency). (2003). Potential of thorium based fuel cycles to constrain plutonium and reduce long lived waste toxicity. IAEA-TECDOC-1349.

IAEA (International Atomic Energy Agency). (2005). Thorium fuel cycle - Potential benefits and challenges. IAEA-TECDOC-1350.

Kang-Mok B. \& Myung-Hyung K. (2005). Core design for heterogeneous thorium fuel assemblies for PWR(I)-nuclear design and fuel cycle economy. Nuclear Engineering and Technology, 37, 91-100.

Koomey J. \& Hultman N.E. (2007). A reactor-level analysis of busbar costs for US nuclear plants, 
1970-2005. Energy Policy, 35, 5630-5642.

Lung M. \& Gremm O. (1998). Perspectives of the Thorium Fuel Cycle, Nuclear Engineering and Design, 180, 133-146.

Rose S.J., Wilson J.N., Capellan N., David S., Guilemin P., Ivanov E., Schneider E.A., Deinert M.R \& Cady K.B. (2011). Minimization of actinide waste by multi recycling of thoriated fuels in the EPR reactor. Annals of Nuclear Energy, 38 (2011) 2619-2624.

SA (SOUTH AFRICA). (2010). Integrated Resource Plan for Electricity 2010-2030.

http://www.energy.gov.za/IRP/irp\%20files/SO_IRP\%2 02010\%20Energy\%20Forecast\%20Final\%20Report. pdf Date of access: 10 June 11.

Schneider E.A., Deinert M.R. \& Cady K.B. (2009). Cost analysis of the US spent nuclear fuel reprocessing facility. Energy Economics, 31, 627-634.

Schram R.P.C. \& Klaassen. (2007). Plutonium management with thorium-based fuels and inert matrix fuels in thermal reactor systems. Progress in nuclear energy, 49, 617-622.

Shelley A., Akie H., Takano H. \& Sekimoto H. (2000). Radiotoxicity hazard of $\mathrm{U}$ free $\mathrm{PuO} 2+\mathrm{ZrO} 2$ and $\mathrm{PuO} 2+\mathrm{ThO} 2$ spent fuels in LWR. Progress in Nuclear Energy, 31, 317-382.

Si S. (2009). Roadmap Design for Thorium-Uranium Breeding Recycle in PWR, Shanghai Nuclear Engineering Research and Design Institute, Shanghai, China IAEA-CN-164-5S09.

Trellue H.R., Bathke C.G. \& Sadasivan P. (2011). Neutronics and material attractiveness for PWR thorium systems using Monte Carlo techniques. Progress in nuclear energy, 53, 698-707.

Van Rooyen M., Mashai P. \& Lydall M. (2012). Thorium: SA's most underestimated energy source? Paper presented at the Thorium and Rare Earths 2012, Cape Town, 22 February.

Weaver K.D. \& Herring J.S. (2002). Performance of Thorium-Based Mixed Oxide Fuels for the Consumption of Plutonium in Current and Advanced Reactors. Paper presented at International Congress on Advanced Nuclear Power Plants (ICAPP), 2002 ANS Annual Meeting, 9 June.

Wilson J.N., Bidaud A., Capellan N., Chambon R., David S., Guillemin P., Ivanov E., Nuttin A \&. Meplan O. (2009). Economy of uranium resources in a three-component reactor fleet with mixed thorium/uranium fuel cycles. Annals of nuclear energy, 36, 404-408.

WNA (World Nuclear Association). (2011). Thorium. http://www.worldnuclear.org/info/inf62.html Date of access: 30 Oct. 2011.

WNA (World Nuclear Association). (2014). http://www.world-nuclear.org/NuclearBasics/Global-number-of-nuclear-reactors/ Date of access: 5 Nov. 2014 